\title{
Technology-Mediated Higher Education Provision during the COVID-19 Pandemic: A Qualitative Assessment of Engineering Student Experiences and Sentiments
}

\author{
Thitiwat Piyatamrong ${ }^{1}$, Jay Derrick ${ }^{2}$, and Abel Nyamapfene ${ }^{3}$ \\ 1,2,3 UCL Institute of Education, University College London, London, UK; ${ }^{2,3}$ UCL Centre for Engineering Education, \\ University College London, London, UK \\ ${ }^{1}$ thitiwat.piyatamrong.19@ucl.ac.uk; ${ }^{2}$ j.derrick@ucl.ac.uk; ${ }^{3}$ a.nyamapfene@ucl.ac.uk
}

\begin{abstract}
The advent of COVID-19 at the beginning of 2020 put universities worldwide into one of the most significant educational disruptions ever experienced. The unrelenting pandemic forced universities to turn to technology to ensure continuity of education. This abruptly changed learning modes for students, with potential implications on the quality of education and the student experience. Therefore, it became necessary to study experiences and sentiments toward learning under the pandemic through the lens of students. Perspectives on the new norm of learning can shed more light on digital technology's roles in learning. The new understanding is potentially useful for conceptualizing future technology-mediated higher education provision. This study follows qualitative research approaches, engaging eleven postgraduate students in three U.K. universities for in-depth semistructured interviews. Thematic analysis is adopted, interpreting sentiments into three interchangeable themes. The findings show that learning during the pandemic has raised many concerns for the future adaptations of online learning. A key finding from this study is that students are generally disappointed by their experiences of online learning effectiveness during the pandemic. One reason for this disappointment is the absence of adequate interactions amongst students due to the reduction in informal student engagement opportunities. The study also suggests that educators need to rethink current technology-mediated education delivery approaches to ensure effective learning. Similarly, students also need to be flexible and openminded, enabling them to adapt to the emerging higher education landscape.
\end{abstract}

Keywords: Education during COVID-19, Education Transformation, Learning and Technology, TechnologyMediated Education

Corresponding Author,

Thitiwat Piyatamrong

University College London (UCL), London, UK

\section{thitiwat.piyatamrong.19@ucl.ac.uk}

\section{Introduction}

The year 2020 is one to be remembered as the year in which the novel COVID-19 pandemic spread and forced most countries into a lockdown state. Since March 23, 2020, when the British government declared a lockdown state, urging the public to stay home, universities have suspended face-to-face teaching and shifted toward providing distance online education. This situation opens doors to acceptance in online learning education and the application of technology to prepare for future changes.

Under the pressing global circumstances, it is assumed that universities could maximize the use of technology through online communication channels to satisfy the missing face-to-face teaching to maintain the standard of education. Laptops and tablets are now being used to recreate classrooms via communications and collaborative software. This scenario has the potential to fundamentally transform higher education through the adoption of digital and online technologies.

At present, there are only a handful of publications that focus on the relationship between COVID-19, education, and technology. A few of these recent publications suggest that COVID-19 experiences will provide an everlasting impact on the world and transform the future of education (Baker, 2020; Di Pietro et al., 2020; Burgess and Sievertsen, 2020). In the research that we report in this paper we seek to contribute to this debate by undertaking an in-depth investigation of the transformations that are unfolding in higher education as a result of the COVID-19 pandemic. Specifically, we seek to explore students' experiences during this pandemic period to determine whether the changes that have been implemented are likely to have a lasting impact on higher education provision.

First and foremost, students initially enrolled in face-to-face, traditional classroom education; however, the pandemic's onset forced learning to abruptly go online. One object of our study is to ascertain the impact of this rapid transformation to online learning on students' 
mindsets and the expectations of their learning experiences. We also wished to establish the extent to which this has obstructed their current education.

The initial stages of defining the research scope showed the disparity between what students had expected and the associated solutions due to COVID-19. As an illustration, higher education students in the United States have publicly voiced their stance against learning online as they have registered for on-campus experiences. Students went to the extent of filing lawsuits against the University of Pennsylvania, Drexel University, and Temple University to stamp on their stance against online education - saying distance learning is not worth the tuition they have paid (Binkley, 2020; Caffrey, 2020).

Along with the abrupt changes in learning experiences, another problem statement concerns students' experiences studying engineering and scientific programs. By not attending on-campus teaching, will lessons and experiences through hands-on practice be obstructed? Learning from home could result in a lack of laboratory studies and limited access to resources. What effect does this have on the learning experiences? How universities have approached this situation is an exciting proposition in this research.

By studying students' experiences and sentiments of their education over the epidemic, this study hopes to provide insights into the future transformation of higher education with digital technology. To satisfy the proposed propositions, this paper explores the following questions:

1. What are students' perceptions and mindsets towards the abrupt of technology-mediated education by universities as a result of the COVID-19 pandemic outbreak?

2. What are the struggles experienced by students during the COVID-19 pandemic outbreak as a result of technology involvement in their education?

3. What is the impact of students' experiences of technology use during the COVID-19 pandemic on the future transformation of higher education?

Given these concerns, this research explores the situation to learn specific details about the experiences and sentiments of postgraduate students in United Kingdombased universities on their use of digital technology in learning through the global crisis. Under a qualitative research approach, this research aims at engaging, in-depth discussions with identified participants to thoroughly learn their experiences. The qualitative analysis of this study looks to interlink the participants' experiences from different backgrounds to derive the themes of this study.

The findings derived from students' experiences on learning under this global pandemic can be summarized as disappointments in learning experiences' effectiveness due to many online learning pedagogy restrictions and the current development of technology. Digital technology is

${ }^{1}$ https://zoom.us/ Online Video Conference, Web Conference focused on being used to communicate and not a tool for enhancing learning experiences. Laboratory learning and hands-on practices were also limited due to proximity protocols. Demographic variables, such as time zone and internet connectivity, remain obstacles in collaborative learning. Although these findings show dissatisfaction in learning experiences, they are all critical lessons for future development - which is the main contribution of this research.

\section{Literature Review}

Baker (2020) discusses a perspective on the Financial Times, stating COVID-19 could profoundly change education for the better. The reasoning behind Baker's statement is during the lockdown, communication and collaborative software are transforming laptop screens into virtual classrooms. In this scenario, students are just finger-clicks away from the knowledge available on Google. Tutors can meet ten or twelve students a day through Zoom. Zhao (2020) supports this statement saying that the pandemic provides rare opportunities for governments and education leaders to rethink education. These education changes highlight the promising future of learning through various modes of delivering quality education (U.N. Policy Brief, 2020).

In response to Baker (2020), the general questions are, would the transformation of educational approaches be this simple? What are the intangibles behind the changes, which are claimed to be profound? Therefore, it is of utmost importance to understand the students' learning experiences under the pandemic and technology roles in these experiences for future transformation. As the pandemic threat gradually disappears, universities tend to want to go back to operating as usual (Zhao, 2020). In reality, the roles of education systems have changed because of COVID-19.

Technology adoption helped to ensure learning continuity (U.N. Policy Brief, 2020). Telecommunication platforms such as Zoom ${ }^{1}$ or Microsoft Teams ${ }^{2}$ (MT) became distance learning modalities (Meyer, 2020; Biavadi, 2020; Pagano and Luglio, 2020). The transition of teaching to available digital technology platforms during the pandemic pushed students to get familiar with online teaching, an approach most students had not taken into proper consideration before (Pagano and Luglio, 2020).

Biavardi (2020) suggests that technologymediated learning had negative impacts on education standards during the quarantine. For instance, Biavardi points to quarantine's psychological effects, which include post-traumatic stress, confusion, and anger - these are all effects of academic education (Brooks et al., 2020). However, despite these concerns on the negative impact of education during COVID-19, a study by Kinash et al. (2015) shows that online or face-to-face lectures do not affect students' achievements. This study looks at digital

${ }^{2}$ https://www.microsoft.com/en/microsoft-365/microsoft-teams/groupchat-software Communication and collaboration platform. 
scholarship, which is the digital evidence such as online resources focusing on open access through a global network establishing digital learning environments (Losoff and Pence, 2009). Long before COVID-19, universities and academics paid attention to online lectures through massive open online courses (MOOCs) as a disruptive and transformative pedagogy, growing at a meteoric rate (Hyman, 2012). Hall and Batty (2020) reinforce social mobility experts' perspectives in their article with warnings that the shift to online could severely hold back some students, such as those from poorer backgrounds and those with disabilities. With the presented circumstances and the availability of MOOCs, the main question is whether education during COVID-19 is a sample for what lies ahead in the upcoming future of education.

Sun et al. (2020) study the transformation of higher education in China, stating universities across China opened 24,000 online courses - 1,291 of China's 'national excellence courses,' the most competitive high-quality courses. Sun says this effort is overlooked by the Chinese Ministry of Education, declaring this event as the testing of distance education on an unprecedented scale. Sun's survey on a questionnaire sample of 39,854 students at Southeast University in China shows that most students are quite happy with online education. This finding is perceivable as an appreciation to online learning management at Southeast University in China; however, the scores reported in this survey contradict the issues raised in past literature and articles on online education effectiveness. As the article by Burns (2020) states, online learning has been disruptive but not in the ways technology companies and educational futurists had imagined as online education had failed to impress its customers - the students. Especially under COVID-19, the abrupt changes, and the scramble towards online teaching cannot be compared to wellplanned and well-designed pedagogy.

The stances from the literature on the effectiveness of online education among higher education communities are ambivalent (Jaggars and Bailey, 2010). With studies showing students are more likely to drop-out of online courses before completion (Beatty-Guenter, 2002), others suggest that students learn as much online as in face-to-face lectures (Kinash et al., 2015; Phipps and Merisotis, 1999; Jung and Rha, 2000). Jung and Rha (2000) accredits online distance learning effectiveness due to different technologies' abilities. However, online education is mainly successful in well-prepared and motivated students (Jaggars and Bailey, 2010).

Digital technologies have been studied as to how academics are utilizing them for teaching. Technology has been described to develop a learner-centered environment in education (Krentler and Williams, 2001, cited by Krentler and Willis-Flurry, 2005). Krentler and WillisFlurry (2005) examined the relationship between the use of technology and student learning to investigate whether technology impacts student learning. This study's findings show that student learning is influenced by using technology and that students would do well to avail themselves of learning opportunities involving technology. As an illustration of learning through digital technology, Bhat et al. (2018) introduce a usability study on E-learning with Google Classroom.

Students' use of digital technology goes beyond assigning technology for a specific task; it is integrated into their daily lives. Learners are often predominantly perceived as using digital technologies for socializing; however, the technology is much applicable and can be used in multiple spaces, including the formal schooling context (Luckin et al., 2009). The perception provided by Luckin et al. defined the potential impact of technology use in learning as tools blurring the boundaries between formal and informal spaces of learning. Luckin termed 'digital dissonance' as a sense where there is a struggle finding an acceptable balance between the social and educational potentials of digital technology. These 'invisible' potentials reshaped the boundaries both teachers and learners might not have realized. For example, in recent years, social media utilization is the main objective. They have also been well integrated as one of the many assisted tools in learning. This could include using social media to share or broadcast content, creating interactive groups, and many other possibilities. As in Chick et al. (2020), a socialmedia-based platform, a closed Facebook group provides daily practice questions to prepare medical students for their American Board of Surgery examination. Grosseck and Holotescu (2008) look at the opportunities of engaging Twitter as a platform for education activities. These resources enhance learning experiences and blurred the boundaries between the formal context and informal contexts of learning. Digital technology in learning experiences over COVID-19 is an exciting proposition to see whether the abrupt changes in education blurred the digital dissonance boundaries even more or whether the pandemic's learning experiences could provide a clearer vision for the future.

In most educational circumstances during COVID-19, teleconference software is applied to conduct lectures, academic conferences, and discussions (Meyer, 2020; Biavadi, 2020; Pagano and Luglio, 2020; Chick et al., 2020). Chick et al. (2020) discussed their solution to surgical education with technology through a flipped classroom strategy. The approach taken was to prerecord videos of lectures for students to watch during any free time. The lecture session over communication software then shifts to synthesis, application, and case-based discussions. As Chick's students are surgical students, the significant decrease in time spent in operating rooms degrades students' practical learning; high-quality surgical videos are recommended to substitute for the practical lessons.

Digital technology implemented from artificial intelligence (AI), virtual reality (VR), and simulation software has also been applied in enhancing learning experiences. Luckin and Holmes (2016) introduced the potential of AI in Education (AIEd) as a powerful 'black box of learning.' Wahyono et al. (2019) experimented on 
the development of artificial intelligence virtual laboratories. The virtual laboratory responds to students' interactions following its implementation, applying expert system algorithmic approaches, an artificial intelligence method for emulating decision-making for instructional strategies, assessments, and evaluations based on the analysis of learners' context. In another illustration, VR designed for entertainment purposes also allows for mental immersion-based applications to see user involvement. This application allows educators to capitalize on VR technology to induce learners' mental immersion in engaging learning activities (Hanson and Shelton, 2008). Illustration of utilizing AI and VR in learning can be described through the application of virtual laboratories. Virtual reality supports comfort in learning hands-on practical knowledge, allowing students to feel the authenticity of the devices and stimulate actual professional experiences (Potkonjak et al., 2016). Stevens Institute of Technology in the USA developed a method for teaching mechanical engineering through a game-based virtual laboratory, allowing students to interact in a virtual environment (Aziz et al., 2014 cited in Potkonjak et al., 2016). This practice provides another option of experiential, hands-on learning, and is another possible option for skill development (Potkonjak et al., 2016). This technology can enhance learning by conveying difficult abstract concepts through the creation of immersive and cognitive learning environments (Huang et al., 2010).

\section{Methodology}

This study adopts a qualitative approach. Under this focus, the methodological approach to research aims to engage in in-depth interviews with identified participants to thoroughly learn their experiences. The participants' experiences look to provide strong arguments in answering the research questions; the qualitative analysis of this study looks to interlink the participants' affairs from different backgrounds to derive the themes of this study.

Semi-structured interviews encourage two-way communication for comprehensive, open-ended thoughts and opinions relating to the topic. This approach supports the learning of critical and actual insights into the questions (Drever, 1995 and Smith, 1995). The general questions in the interviews remained open-ended to encourage participants to express feedback on their experiences. The interviews in this study are flexible and provide an emphasis on how the participants understand their given circumstances - that is, the focus was more on what the participants felt was necessary for explaining their experiences (Bryman and Bell, 2011).

\section{A. Participants}

The primary data for this research is drawn from the experiences of postgraduate students in U.K. universities. The participants recruited for this study are from different academic programs. The reasoning behind recruiting participants of varying backgrounds is to learn about the differences in approaches and concerns of each educational program. It is assumed that different academic fields of study process their unique ways of learning, the role of technology in delivering the learning experiences should be customized to their field of study. The participants' details include codenames, institution, their home country, and whether the participants remained in the United Kingdom over the pandemic. The recorded data fields of the home country and whether the participants remained in the United Kingdom over the epidemic relates to the experiences of the participants as ethnographic variable plays an essential role in the learning experiences for distance learning.

Out of the 11 participants, eight are postgraduate students in engineering and technology subjects. The eight participants studying engineering-related disciplines follow these codenames; $\mathrm{Da}(\mathrm{D})$, Jane $(\mathrm{J})$, Sandy (Sa), Sharon (Sh), San (S), Victor $(V)$, Pan $(P)$, and Lana $(L)$.

\section{B. Data Collection and Analysis}

This study follows the ethical research guidelines by the British Education Research Association - BERA standards (BERA, 2018). The process includes informed consent, which was signed off by all the participants before the interviews. The participants were informed of the voice recordings and the anonymous identity of their participation. The conducted interviews resemble friendly discussions over the topic. The participants seem relaxed as they did not show any signs of anxiety.

Semi-structured interviews were conducted to learn in-depth on the actual experiences of participants under the research questions. The interviews are analyzed following discourse analysis and thematic analysis. Through the interviews, each discussion was recorded and transcribed. The data are coded by the themes of the topic, which were brought up by participants. Before defining codes for all the transcriptions, notes on key points were added to the transcripts' context. With similar questions, different participants from different data samples shed light on the concerns of similar topics. These topics are then further studied following existing literature to see how other literature has discussed the issues. Most of the coded context could further provide critical stances in answering the proposed research questions. Another finding in data analysis is the importance of the ethnographic feature. In terms of ethnography, the participants are international students. This feature of the data was found relating to the participants' learning experiences through differences in time-zones, internet connection capabilities, and restricted access to the internet - which are imposed by different geographical locations, resulting in substantial impacts on the overall learning experiences of students. 


\section{Findings and Discussions}

The findings in this chapter feature key arguments from participants following the thematic analysis. From the data samples, this research identifies the following themes:

1. Online Learning Pedagogy and The Roles of Digital Technology

2. Learning Environments and The Roles of Educators

3. Experiences Toward Future Transformations.

A. Online Learning Pedagogy and The Roles of Digital Technology

With online pedagogy, participants in this study argue that there are many struggles with the effectiveness of learning online. Although the image of online education over video conferencing and recording applications might seem convenient and convincing, many intangibles affect the effectiveness of learning under this platform. The learning experience was not well rounded - this is interpreted as from the lack of student preparedness for online learning.

\begin{abstract}
My main problem, as an international student, some words the lecturer spoke really fast. Even when I went back over it a few times, I still could not know what that word is or what it means. Certain times, when the lecturer teaches, he is also writing on the whiteboard.... The clip only shows the PowerPoint slides - so what is written can't be seen. So, the written formula or the chemical components on the whiteboard is missing. (D)
\end{abstract}

A contributing factor to the difficulties students experienced with online learning are the changes to assessment that lecturers were forced to implement as a result of the move to online learning:

This was difficult for engineering coursework we are focusing on the calculation, but for coursework, we had to avoid the difficulties in calculations, so the professor wanted to check on writing essay, and approach the coursework by explaining in words and not calculations.(Sh)

Understandably, the pandemic might have tied the hands of educators and institutions. However, preparing online learning pedagogy is critical in maintaining education standards. The points raised in these statements could be due to the global uncertainties; however, these student perspectives point to the lack of preparedness for online pedagogies, both on the part of students and lecturers. More emphasis needs to be placed on preparing both students and lecturers for online learning to continue in the coming academic year.
Participants implied that the adopted online learning pedagogy over COVID-19 was mainly characterized by the direct transfer of existing teaching strategies to the online environment. In this case, lecturers simply adopted digital technologies as a replacement for the missing physical learning environments, with the learning process remaining the same. This resulted in ineffective learning when compared to traditional face-toface learning environments. Consequently, students are the ones who lose out on learning opportunities.

We used technology for communication but not for improving learning experiences. $(P)$

\section{B. Learning Environments and The Roles of Educators}

The learning environments and the roles of educators are critical to the overall learning experiences. Offir et al. (2002) suggest that advanced technological platforms and delivery systems have turned distance learning into an economically feasible means of stretching classroom learning. For the educators during the COVID19 pandemic, this is a challenge as they have to contend with adapting quickly to multiple digital protocols in creating and delivering learning approaches suitable for the digital environment. Educators' roles and how they utilize digital tools in teaching are found to be the heart and soul of the future of online learning. The concerns raised under the theme of learning pedagogy and digital technology lead back to the need to understand educators' roles.

Connection is a big issue, but it will be improved in the coming years. The hardware can be improved, but the soft skills side must be supported by more strategies and online tours of applications to support online teaching. $(L)$

Eventually, technology will improve and become more advanced; how skills are developed to support learning strategies will define future education's impact.

The move to online learning as a result of COVID-19 also had an impact on the learning of technical skills This is poignant for engineering where a huge emphasis is placed on the acquisition of technical skills. Specifically, the running of laboratories and teaching of hands-on practical skills proved to be a challenge under the stay home protocols introduced during the pandemic period.

The university replaced laboratory studies with 'dry-lab'; - in this case, is like imagining doing the lab work in your head. We are supposed to imagine working in labs and using the tools independently. For example, chemistry laboratory, typically, we would pick up chemicals, put them together in microscopy to see the reactions and molecules depending on the subject. Because of the pandemic, lab works by giving out problems such as, given two chemical components and create a product. We are to 
approach it with 'dry-lab.' This is done through imaginations in our heads. Then write down on paper explaining how this lab is to be done through your imaginations. What tools are needed, what chemicals and how much to use it, how is it done... This practice used many more tools than what I have experienced with. A lot of the tools, I don't even know the names. So, without prior knowledge and I had to practice dry-lab and imagine every single step in my head - it was almost impossible. (D)

The experience of $(D)$ is similar to those reported by Chick et al. (2020) when the hands-on practice was replaced by having students watch video recordings of practical activity demonstrations. Whilst some researchers, such as Potkonjak et al.(2016), express the view that software and digital technology can make up for missing hands-on learning, this was not the view of participants in this study. Instead, participants felt that online learning is not as efficient as going to the laboratory.

There are many other physical challenges to simulating the actual experience of hands-on practice. For instance, with respect to dry-lab, students experienced difficulties in imagining the detailed factors of light, temperature, and moisture that are needed when solving problems. On the positive side, the dry-lab approach requires students to truly understand the theories and practical knowledge, from start to finish, to solve a situated laboratory problem effectively. Hands-on practice will remain difficult for distance learning without adequate tools. Adaptations are thus necessary to find new approaches.

This study suggests that switching to online learning environments significantly affect the learning experiences of students. There are many variables and factors that affect the learning experience thoroughly. The global pandemic calls on education systems, educators, and students to rethink their approaches and education roles for effective online learning.

\section{Experiences Toward Future Transformations}

The experiences and sentiments shared by participants described under the previous themes show possibilities of understanding the outlook of educational systems to prepare for future transformations. The transformations of education systems can be perceived as both long-term strategic frameworks and short-term plans to recontextualize for satisfying learning under the current pandemic.

On the findings for future long-term transformations, the participants have raised the following suggestion on a technical perspective;

In the future, if technology can extend more than now, I think it might help to get more from online learning in a short time. If it can help with the points, I struggled with. It would be better. Communications, connections, or if $V R$ or AR is applied in education, help integrates with education activities and online activities. $(P)$

The future of VR and augmented reality (AR) provides possibilities where the rendered surrounding environments provide a simulation as if the user is in an actual classroom. This concept is similar to the study by Hanson and Shelton (2008).

The E.U. Technical Report of Di Pietro et al. (2020), which reflects on the impact of COVID-19 on education, raises similar pandemic effects on education, such as changes in interactions and the lack of learning motivations. However, research by Di Pietro focused on these aspects and their effect on societal and economic concerns. In this research, the primary purpose is to reflect on the sentiments to satisfy effective education and the best learning experiences. To encapsulate the sentiments raised by participants, the missing key to effective education is the lack of interactions and socialization in current COVID-19 era online learning. This can be resolved by redesigning online learning pedagogies, motivating students to participate in online classes, and redesigning online learning environments.

Whist the sentiments expressed by participants that online learning degraded their learning experiences, it is also apparent that these sentiments also suggest that students found it difficult to adapt to the changing education environment. Therefore, this study suggests that the transformation to online learning requires openmindedness from educators and students in accepting and adapting to new approaches.

\section{Conclusions}

Digital technology has played a vital role in providing continuity of education delivery via online learning platforms during the COVID-19 pandemic. Indeed, education futurists believe that digital technology has an unlimited potential to transform learning. However, as this study shows, more effort needs to be invested in identifying and overcoming potential online learning obstacles.

Participants' experiences and sentiments of online learning show the degradation of higher education students' expectations, which were set before enrolling in postgraduate programs. Participants expressed unhappiness with the lack of socialization opportunities, the missing opportunities to learn tacit knowledge, and the limited opportunities to build upon social connections. Most importantly, for engineering students, the lack of opportunities to practice practical hands-on skills led to student dissatisfaction with online learning provision.

However, we believe that research on the nature and quality of education provision during the COVID-19 
pandemic contributes significantly to a new understanding of utilizing technology in transforming education. In conclusion, this study suggests that it is now time to reimagine pedagogical approaches and digital technology's roles for effective learning.

\section{Acknowledgment}

This study is funded in part by the Royal Thai Government Scholarship. The authors wish to thank the interviewees of this study.

\section{References}

Baker, K. (2020). Covid-19 is changing education for the better, Financial Times. Available at: https://www.ft.com/content/51496fde-98e7-11ea-871bedeb99a20c6e Accessed on September 1, 2020.

Beatty-Guenter, P. (2002). Why distance education? Mimetic forces in institutions of adult education, $21^{\text {st }}$ Annual National Conference of the Canadian Association for the Study of Adult Education, Toronto, Ontario.

BERA (2018). Ethical Guidelines for Educational Research, London: British Educational Research Association, $4^{\text {th }}$ Edition.

Bhat, S., Raju, R., Bikramjit, A., and D'Souza, R. (2018) Leveraging E-Learning through Google Classroom: A Usability Study, Journal of Engineering Education Transformations, Volume 31, No. 3.

Biavardi, N.G. (2020). Being an Italian Medical Student During the COVID-19 Outbreak, International Journal of Medical Students, Vol 8. Issue 1.

Binkley, C. (2020). Unimpressed by Online Classes. Students at 26 Schools, Including Drexel, File Lawsuits, NBC Philadelphia, Available at: https://www.nbcphiladelphia.com/news/coronavirus/u nimpressed-by-online-classes-students-at-26-schoolsincluding-drexel-file-lawsuits-and-seek-refunds/2383730/ Accessed on September 1, 2020.

Brooks, S.K., Webster, R.K., Smith, L.E., Woodland, L., Wessely, S. Greenberg, N., Rubin G.J. (2020). The psychological impact of quarantine and how to reduce it: rapid review of evidence. Lancet. 395(10227):912-920

Bryman, A. and Bell, E. (2011). Business Research Methods, Oxford University Press, $3^{\text {rd }}$ Edition.

Burgess, S. and Sievertsen, H.H. (2020). Schools, skills, and learning: The impact of COVID-19 on education, VoxEU.org, Available at: https://voxeu.org/article/impactcovid-19-education Accessed on September 2, 2020.

Burns, M. (2020). Online Education Covid-19's struggle, UKFIET - The Education and Development Forum, Available at: https://www.ukfiet.org/2020/online- educations-covid-19-

struggles/?fbclid=IwAR18V1OAXao41JCjOdanEn5SDw wTcqZqiYFzbAnrt_EMYe_ayQcXEev69Hg Accessed on September 1, 2020.

Chick, R.C. et al. (2020). Using Technology to Maintain the Education of Residents During the COVID_19 Pandemic, Journal of Surgical Education, Volume 77, Number 4.

Di Pietro, G., Biagi, F., Costa, P. Karpinski, Z., Mazza, J. (2020). The likely impact of COVID-19 on education: Reflections based on the existing literature and recent international datasets, JRC Technical Report, European Commission.

Drever, E. (1995). Using Semi-Structured Interviews in Small-Scale Research. A Teacher's Guide, in Scottish Council for Research in Education, Edinburgh. Pg 98, ISBN-1-86003-011-4.

Grosseck, G. and Holotescu, C. (2008). Can we use Twitter for educational activities? The $4^{\text {th }}$ International Scientific Conference eLearning and Software Education, Bucharest, April 17 - 18, 2008.

Hall, R. and Batty, D. (2020) 'I can't get motivated: the students struggling with online learning, The Guardian, Available at: https://www.theguardian.com/education/2020/may/04/icant-get-motivated-the-students-struggling-with-onlinelearning?fbclid=IwAR2kfpuhs3H5ramcOs0ScxzKdimqxwEpzAJ24aGLmCtROpIlJRj43eNO8 Accessed on September 4, 2020.

Hanson, K. and Shelton, B.E. (2008). Design and development of virtual reality: analysis of challenges faced by educators, Education Technology and Society, 11(1), $118-131$.

Huang, H.M., Rauch, Ulrich, R., and Liaw, S.S. (2010). Investigating learners' attitudes toward virtual reality learning environments: Based on a constructivist approach, Computers and Education 55(2010), 1171 - 1182.

Hyman, P. (2012). In the year of disruptive education, Communications of the ACM, 55(12), $20-22$.

Jaggars, S.S. and Bailey, T. (2010). Effectiveness of Fully Online Courses for College Students: Response to a Department of Education Meta-Analysis, Community College Research Center, Teachers College, Columbia University.

Jung, I. and Rha, I. (2000). Effectiveness and CostEffectiveness of Online Education: A Review of the Literature, Educational Technology, Vol. 40, No. 4.

Kinash, S., Knight, D., and McLean, M. (2015). Does Digital Scholarship through Online Lectures Affect Student Learning? Educational Technology and Society. 18(2): $129-139$. 
Krentler, K.A. and Willis-Flurry, L.A. (2005). Does Technology Enhance Actual Student Learning? The Case of Online Discussion Boards, Journal of Education for Business, 80:6, 316 - 321 .

Losoff, B. and Pence, H.E. (2009). Digital scholarship and open access. Journal of Education Technology Systems, $38(2), 95-101$.

Luckin, R., Mee, A., and Oliver, M. (2009). Beyond Web 2.0: Mapping the technology landscapes of young learners, Journal of Computer Assisted Learning, 25, 56 - 69.

Luckin, R., Holmes, W., Griffiths, M., and Forcier, L.B. (2016). Intelligence Unleashed: An argument for AI in Education. Pearson Education, London.

Meyer, K. (2020) ZOOM - Supporting Education with Online Learning Solutions, Connect Online, Available at: https://connect.geant.org/2020/04/08/zoom-supportingeducation-with-online-learning-solutions Accessed on September 1, 2020.

Offir, B., Barth, I., Lev, Y., and Shteinbok, A. (2003). Teacher-student interactions and learning outcomes in distance learning environment, The Internet and Higher Education, Vol. 6.

Pagano, G. and Luglio, G. (2020). Medical Education in Naples, Itlay, at the Time of SARS-CoV-2, International Journal of Medical Students, Vol. 8, Issue 1.

Phipps, R. and Merisotis, J. (1999). What's the difference? A review of contemporary research on the effectiveness of distance learning in higher education, Washington D.C.: Institute for Higher Education Policy.

Potkonjak, V., Gardner, M., Callaghan, V., Mattila, P., Guetl, C., Petrovic, V.M., and Jovanovic, K. (2016). Virtual laboratories for education in science, technology, and engineering: A review, Computers \& Education, 95, $309-327$.

Smith, J. A. (1995). Semi structured interviewing and qualitative analysis. In: Smith, Jonathan A. and Harre, R. and Van Langenhove, L. (eds.) Rethinking Methods in Psychology. Sage Publications, pp. 9-26.

Sun, L., Tang, Y., and Zuo, W. (2020). Coronavirus Pushes Education Online, Nature Materials, 19, 687.
UN Policy Brief. (2020). Policy Brief: Education during COVID-19 and beyond, United Nations.

Wahyono, I.D., Putranto, H., Saryono, D., Asfani, K., and Sunarti (2019). Development of a Personalized Virtual Laboratory Using Aritificial Intelligent, Proceedings of the International Conference on Learning Innovation 2019 in Advances in Social Science, Education, and Humanities Research, Volume 446.

Zhao, Y. (2020). COVID-19 as a catalyst for educational change, PROSPECTS Comparative Journal of Curriculum, Learning, and Assessment. 